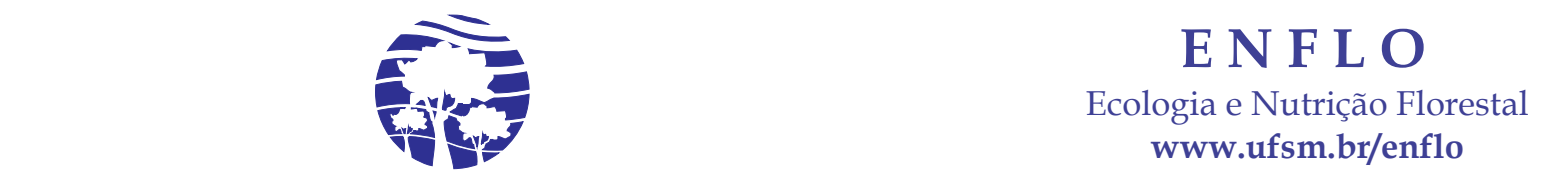

\title{
Fertilização mineral e calagem no crescimento de mudas de Eucalyptus camaldulensis ${ }^{1}$
}

\author{
Cristiane Ramos Vieira ${ }^{2}$; Oscarlina Lúcia dos Santos Weber ${ }^{3}$
}

\begin{abstract}
Resumo: A utilização de substratos pode garantir mudas com características morfológicas adequadas para o plantio no campo. Diante disso, realizou-se experimento em viveiro com o objetivo de avaliar a influência da utilização de calcário e diferentes formulações de adubos na produção de mudas de Eucalyptus camaldulensis. As mudas da espécie foram produzidas em tubetes com capacidade para $160 \mathrm{~cm}^{3}$, oriundas de sementes que foram colocadas para germinar em areia e vermiculita. Ao atingirem $15 \mathrm{~cm}$ de altura, as plantas foram transplantadas para os tratamentos testados: T1 - 100\% Plantmax $\mathbb{B}$; T2 Plantmax ${ }^{\circledR}+$ NPK + calcário; T3- Plantmax ${ }^{\circledR}+$ calcário + N; T4 - Plantmax ${ }^{\circledR}+$ calcário + P; T5 - Plantmax ${ }^{\circledR}+$ calcário + K; T6 - Plantmax ${ }^{\circledR}$ + N; T7 - Plantmax ${ }^{\circledR}+$ P; T8 - Plantmax ${ }^{\circledR}$ + K; T9 - Plantmax ${ }^{\circledR}$ + calcário, com dez repetições, dispostos em delineamento inteiramente casualizado. A avaliação do crescimento se deu 90 dias após o começo das análises, com as medições de: altura, diâmetro de coleto, biomassa e, concentrações de macronutrientes e de B. Verificou-se que é importante atentar para a utilização de Plantmax ${ }^{\circledR}$ como substrato, pois o mesmo não disponibiliza nutrientes em concentrações adequadas para todas as espécies. As melhores condições para a produção de mudas de E. camaldulensis foi com substrato contendo Plantmax ${ }^{\circledR}+$ calcário + N; Plantmax ${ }^{\circledR}+$ calcário + P; Plantmax ${ }^{\circledR}+\mathrm{N}$; ou Plantmax ${ }^{\circledR}+\mathrm{P}$.
\end{abstract}

Palavras-chave: Eucalyptus camaldulensis; Nutrição Florestal; Produção de Mudas.

\section{Mineral fertilization and limestone on the growth of Eucalyptus camaldulensis seedlings}

\begin{abstract}
The use of substrates can produce seedlings with adequate morphological characteristics for planting in the field. Therefore, experiment was realized in a nursery in order to evaluate the use of limestone and different fertilizer formulations on the production of Eucalyptus camaldulensis seedlings. The seedlings of the specie were produced in tubetes with a capacity to $160 \mathrm{~cm}^{3}$, originating of seeds that were placed to germinate in sand and vermiculite. When they reach $15 \mathrm{~cm}$ of height, the plants were transplanted for the treatments tested: T1 - 100\% Plantmax ${ }^{\circledR} ;$ T2 - Plantmax ${ }^{\circledR}+$ NPK + lime; T3 Plantmax ${ }^{\circledR}+$ lime + N; T4 - Plantmax ${ }^{\circledR}+$ lime + P; T5 - Plantmax ${ }^{\circledR}+$ lime + K; T6 - Plantmax ${ }^{\circledR}+$ N; T7 - Plantmax ${ }^{\circledR}+$ P; T8 - Plantmax ${ }^{\circledR}$ + K; T9 - Plantmax ${ }^{\circledR}+$ limestone, with ten replications in a completely randomized design. The growth evaluation occurred 90 days after the start of analysis with the measuring height, diameter collect, biomass and, concentrations of macronutrients and B. It was verify that is important to consider the use of Plantmax ${ }^{\circledR}$ as substrate, because it does not release nutrients in adequate concentrations for all species. The best conditions for the seedlings production of $E$. camaldulensis were with substrate containing Plantmax ${ }^{\circledR}+$ calcário $+\mathrm{N}$; Plantmax ${ }^{\circledR}+$ calcário + P; Plantmax ${ }^{\circledR}+\mathrm{N}$; or Plantmax ${ }^{\circledR}+\mathrm{P}$.
\end{abstract}

Keywords: Eucalyptus camaldulensis; Forest Nutrition; Seedlings Production.

\footnotetext{
${ }^{1}$ Recebido em 25.05.2017 e aceito para publicação como artigo científico em 26.06.2017.

${ }^{2}$ Engenheira Florestal, Dr ${ }^{a}$. Professora do curso de Agronomia da Universidade de Cuiabá - UNIC. E-mail: <cris00986@ hotmail.com>. ${ }^{3}$ Engenheira Agrônoma, Dra ${ }^{\mathrm{a}}$. Professora Associada do Departamento de Solos e Engenharia Rural - FAAZ/UFMT. E-mail: <oscsan@uol.com.br>.
} 


\section{Introdução}

A área plantada com Eucalyptus no Brasil atingiu 5,6 milhões de hectares no ano de 2015, total de 5.630.607 hectares, o que representa $72 \%$ do total de árvores plantadas. A maior parte desse plantio concentra-se nos estados de Minas Gerais com $25 \%$ e, São Paulo com 17\% (IBA, 2016).

Uma das espécies de eucaliptos plantada no Brasil é o Eucalyptus camaldulensis Dehn, nativa da Austrália e bastante utilizada em plantios comerciais devido a sua rusticidade e a sua adaptabilidade às condições de baixa fertilidade. De acordo com Del Quiqui et al. (2001), a espécie apresenta ampla distribuição geográfica e pode ocupar diversos ambientes ecológicos, é tolerante a inundações temporárias e resistente a temperaturas elevadas. Segundo esses autores, a espécie pode ser indicada para zonas críticas, onde as deficiências hídricas e problemas ligados ao solo sejam fatores limitantes. A madeira de E. camaldulensis é de cor avermelhada e densidade similar à do $E$. cloeziana, dura, muito durável e resistente aos cupins, sendo apta para dormentes, construções pesadas, óleo essencial, marcenaria, tanino, carvão (MORAES NETO, 2008).

As características da espécie e sua adaptabilidade a solos de baixa fertilidade a condicionam ao plantio em área de Cerrado. No entanto, a maioria dos solos de Cerrado, principalmente os Latossolos, possuem elevada acidez, altos teores de Al trocável, baixa disponibilidade de cátions básicos como $\mathrm{Ca}$ e $\mathrm{Mg}$, além de baixa disponibilidade de $\mathrm{P}$ na forma disponível para as plantas e de micronutrientes como B e Cu. Portanto, são desfavoráveis ao crescimento das plantas, sendo fundamental a utilização do calcário para elevar o pH, a capacidade de troca de cátions e a disponibilização de nutrientes, como enfatizado por Favare et al. (2012), Costa Filho et al. (2013) e Oliveira et al. (2015).

Por isso, quando se utiliza, substrato de baixa fertilidade para produção de mudas, a aplicação de corretivos e adubos se torna necessária (FAVARE et al., 2012), para garantir maior qualidade, o que refletirá na produtividade e estabelecimento dos plantios florestais (CARLOS et al., 2014). No entanto, o conhecimento das exigências nutricionais da espécie também se faz necessário (FEITOSA et al., 2011).

$\mathrm{Na}$ produção de mudas, a composição do substrato deve ser uma das maiores preocupações, pois, um de seus objetivos é fornecer às plantas os nutrientes que estas precisam para crescer até estarem aptas para o plantio no campo. Por isso, esses nutrientes devem estar prontamente disponíveis e em concentrações adequadas e compatíveis com as necessidades da espécie.

Existem no mercado, substratos recomendados para a produção de espécies florestais, porém, a sua formulação não considera a especificidade das demandas nutricionais. De acordo com Scheer et al. (2010), os substratos comerciais nem sempre fornecem quantidades satisfatórias de nutrientes, precisando ser enriquecidos com fertilizantes, por isso, pode-se não obter o resultado esperado com a utilização apenas desses produtos durante a produção de mudas.

Visando conhecer essas demandas algumas pesquisas foram realizadas por Muniz et al. (2013), que recomendaram a aplicação de $3 \mathrm{~kg}$ do fertilizante Osmocote $19-06-10$ por $\mathrm{m}^{3}$ do substrato comercial BioPlant ${ }^{\circledR}$ na produção de mudas de E. camaldulensis. E por Lôbo et al. (2014) que testaram diferentes doses de NPK no crescimento de mudas de E. camaldulensis e verificaram que o maior crescimento em diâmetro, altura, comprimento radicular e matéria seca na parte aérea se deu na dose de 9 $\mathrm{kg}$ do fertilizante por $\mathrm{m}^{3}$ de substrato.

Porém, poucas são as informações disponíveis sobre a adubação NPK e a calagem na produção de mudas de E. camaldulensis. Diante disso, realizou-se experimento com o objetivo de avaliar o crescimento de mudas de $E$. camaldulensis em substrato comercial enriquecido com N, P, K e calcário. 


\section{Material e métodos}

$\mathrm{O}$ experimento foi instalado em casa de vegetação, construída de material telado tipo sombrite branco e coberta com telha de amianto, sem controle de temperatura, localizada na Faculdade de Agronomia, Medicina Veterinária e Zootecnica (FAMEVZ) da Universidade Federal de Mato Grosso (UFMT), em Cuiabá.

As sementes de E. camaldulensis foram coletadas de 20 árvores matrizes espaçadas em $100 \mathrm{~m}$ em plantio localizado no município de Dom Aquino-MT. Quatro a cinco destas sementes foram colocadas para germinar em tubetes com capacidade para $160 \mathrm{~cm}^{3}$, preenchidos com areia lavada e vermiculita. Após a germinação e atingirem $5 \mathrm{~cm}$ de altura, $o$ que ocorreu aos 30 dias depois da semeadura, realizou-se o raleamento, mantendo-se apenas uma planta por tubete. Ao atingirem $15 \mathrm{~cm}$ de altura, as plantas foram transplantadas para os tubetes de polipropileno de formato cônico com estrias, perfurados na extremidade inferior, com capacidade para $280 \mathrm{~cm}^{3}$, preenchidos com as combinações de substratos utilizadas no experimento e mantidas por 15 dias para adaptação. Esse período de adaptação foi compatível com o de emissão de novas brotações.

$O$ substrato comercial utilizado foi $o$ Plantmax $®$, indicado para produção de mudas de espécies florestais. Em sua composição constam: casca de pinus, vermiculita de granulometria fina e superfina e húmus. Amostras do substrato foram retiradas para a realização das análises químicas, segundo métodos da Embrapa (1997) e apresentadas na Tabela 1.

Tabela 1 - Características químicas do substrato comercial utilizado para produção de mudas de Eucalyptus camaldulensis Table 1- Chemical characteristics of commercial substrate using to production of Eucalytus camaldulensis seedlings

\begin{tabular}{|c|c|c|c|c|c|c|c|c|c|c|c|c|}
\hline $\mathbf{p H}^{*}$ & H+Al & Al & $\mathbf{C a}$ & Mg & $\mathbf{K}$ & $\mathbf{P}$ & SB & TрН7,0 & CTCt & V & m & $\mathbf{N}$ \\
\hline $\mathrm{CaCl}_{2}$ & & $\mathrm{~mol}$ & $\mathrm{~m}^{-3}$ & & $--\mathrm{m}$ & $-3--$ & & $\mathrm{cmol}_{\mathrm{c}} \mathrm{dm}$ & & & & $\mathrm{g} \mathrm{kg}^{-1}$ \\
\hline 5,9 & 6,8 & 0,1 & 8,6 & 6,8 & 22,5 & 62,2 & 15,5 & 22,3 & 15,6 & 69 & 0,6 & 6,4 \\
\hline
\end{tabular}

*pH em $\mathrm{CaCl}_{2}$ - relação 1:2,5; $\mathrm{H}+\mathrm{Al}$ - em acetato de cálcio; $\mathrm{Al}^{3+}, \mathrm{Ca}^{2+}$ e $\mathrm{Mg}^{2+}$ - em KCl; $\mathrm{P}$ e $\mathrm{K}$ - em Mehlich; $\mathrm{SB}$ - soma de bases; T $(\mathrm{pH} 7,0)$ - capacidade de troca de cátions a pH 7,0; CTCt - capacidade efetiva de troca de cátions; V\% - saturação por bases, em \%; m\% saturação por $\mathrm{Al}$, em \%; $\mathrm{N}$ - digestão sulfúrica.

Esse substrato foi enriquecido com NPK e calcário, compondo os seguintes tratamentos: T1 - 100\% Plantmax ${ }^{\circledR} ;$ T2 - Plantmax ${ }^{\circledR}+$ NPK + calcário; T3- Plantmax ${ }^{\circledR}+$ calcário + N; T4 Plantmax ${ }^{\circledR}+$ calcário + P; T5 - Plantmax ${ }^{\circledR}+$ calcário + K; T6 - Plantmax ${ }^{\circledR}+\mathrm{N} ; \mathrm{T} 7$ Plantmax ${ }^{\circledR}+$ P; T8 - Plantmax ${ }^{\circledR}+\mathrm{K}$; T9 Plantmax ${ }^{\circledR}+$ calcário, originando nove tratamentos e dez repetições, dispostos em delineamento inteiramente casualizado.

A adição de $\mathrm{N}, \mathrm{P}$ e $\mathrm{K}$ foi realizada com base nas exigências da espécie, descrita por Gonçalves (1995): $150 \mathrm{~g}$ de $\mathrm{N}, 300 \mathrm{~g}$ de $\mathrm{P}_{2} \mathrm{O}_{5} \mathrm{e}$ $100 \mathrm{~g}$ de $\mathrm{K}_{2} \mathrm{O}$ por cada $\mathrm{m}^{3}$ de substrato, para mudas em tubetes. Como fonte de $\mathrm{N}$ utilizou-se a ureia; de $\mathrm{P}_{2} \mathrm{O}_{5}$, o superfosfato simples e; de $\mathrm{K}_{2} \mathrm{O}$, o cloreto de potássio.

Após o transplante das mudas e do período de adaptação de 15 dias, realizou-se o acompanhamento do crescimento das plantas de E. camaldulensis por 90 dias em função dos substratos testados.

Ao término do experimento realizaram-se as biometrias das características morfológicas: altura $(\mathrm{H})$, em $\mathrm{cm}$, medindo a $5 \mathrm{~cm}$ da superfície do solo até a última folha; diâmetro de colo (DC), em mm, medido com paquímetro digital e; o comprimento da raiz, medindo a raiz principal (mais desenvolvida) desde a sua inserção na região do colo até a ponta. Para obtenção da biomassa, as mudas foram retiradas do substrato, seccionadas em folhas, caule e raízes e, em seguida, as raízes foram lavadas em água corrente. $\mathrm{O}$ material vegetal foi levado à estufa de circulação forçada de ar a $65^{\circ} \mathrm{C}$ até peso constante e após secagem foi pesado em balança analítica com precisão de $0,01 \mathrm{~g}$.

O material seco foi moído em moinho tipo 
Wiley, para posteriores determinações das concentrações foliares de macronutrientes e de B, após as digestões sulfúrica e nitro-perclórica, seguindo métodos de Malavolta et al. (1997). A saber: $\mathrm{N}$ total por semi-micro Kjeldahl; $\mathrm{P}$ por colorimetria do metavanadato; $\mathrm{S}$ por turbidimetria do sulfato de bário; $\mathrm{K}$ por fotometria de chama de emissão; $\mathrm{Ca}$ e $\mathrm{Mg}$ por quelatometria com EDTA e; B por colorimetria da azometina $\mathrm{H}$.

Os dados foram interpretados por meio da análise de variância e a comparação de médias foi realizada pelo método de Tukey ao nível de $5 \%$ de probabilidade de erro utilizando o programa estatístico Assistat 7.6 beta, da UFCG (SILVA e AZEVEDO, 2011), após constatação da normalidade dos mesmos.

\section{Resultados e Discussão}

Crescimento das mudas de Eucalyptus camaldulensis

Os dados de crescimento e produção de biomassa das mudas de E. camaldulensis estão apresentados na Tabela 2, demonstrando que, como existem diferentes demandas nutricionais entre as espécies florestais, nem sempre os substratos comerciais favorecem $\mathrm{o}$ maior crescimento, devendo estes, portanto, serem adubados para que a espécie atinja seu máximo potencial produtivo.

Tabela 2 - Crescimento em altura $(\mathrm{cm})$, em diâmetro $(\mathrm{mm})$, comprimento da raiz $(\mathrm{cm})$, biomassa das folhas $(\mathrm{g})$, do caule $(\mathrm{g})$ e da raiz (g) das mudas de Eucalyptus camaldulensis em combinações de substrato comercial, adubo e calcário

Table 2 - Growth in height $(\mathrm{cm})$, diameter $(\mathrm{mm})$, root length $(\mathrm{cm})$, leaves $(\mathrm{g})$, stem $(\mathrm{g})$ and root biomass $(\mathrm{g})$ of Eucalyptus camaldulensis seedlings in commercial substrate, fertilizer and limestone combinations

\begin{tabular}{ccccccc}
\hline Tratamento* & H & DC & Raiz & Folha & Caule & Raiz \\
\hline T1 & $28,67 \mathrm{ab}^{*}$ & $2,77 \mathrm{ab}$ & $27,83 \mathrm{a}$ & $1,59 \mathrm{a}$ & $0,56 \mathrm{a}$ & $0,58 \mathrm{abcd}$ \\
T2 & $31,00 \mathrm{ab}$ & $2,48 \mathrm{abc}$ & $25,17 \mathrm{a}$ & $1,11 \mathrm{bcd}$ & $0,38 \mathrm{bc}$ & $0,48 \mathrm{~cd}$ \\
T3 & $31,67 \mathrm{ab}$ & $3,02 \mathrm{a}$ & $26,33 \mathrm{a}$ & $1,25 \mathrm{ab}$ & $0,54 \mathrm{ab}$ & $0,65 \mathrm{abc}$ \\
T4 & $34,33 \mathrm{a}$ & $2,82 \mathrm{ab}$ & $29,67 \mathrm{a}$ & $1,20 \mathrm{ab}$ & $0,37 \mathrm{c}$ & $0,78 \mathrm{ab}$ \\
T5 & $33,50 \mathrm{a}$ & $2,28 \mathrm{bc}$ & $25,00 \mathrm{a}$ & $1,18 \mathrm{abc}$ & $0,32 \mathrm{~cd}$ & $0,73 \mathrm{abc}$ \\
T6 & $33,17 \mathrm{a}$ & $2,62 \mathrm{abc}$ & $27,67 \mathrm{a}$ & $1,32 \mathrm{ab}$ & $0,40 \mathrm{abc}$ & $0,59 \mathrm{abcd}$ \\
T7 & $32,00 \mathrm{a}$ & $2,40 \mathrm{abc}$ & $23,83 \mathrm{a}$ & $1,24 \mathrm{ab}$ & $0,41 \mathrm{abc}$ & $0,81 \mathrm{a}$ \\
T8 & $23,50 \mathrm{bc}$ & $2,03 \mathrm{c}$ & $29,67 \mathrm{a}$ & $0,75 \mathrm{~d}$ & $0,19 \mathrm{de}$ & $0,51 \mathrm{bcd}$ \\
T9 & $20,00 \mathrm{c}$ & $1,33 \mathrm{~d}$ & $25,00 \mathrm{a}$ & $0,78 \mathrm{~cd}$ & $0,08 \mathrm{e}$ & $0,31 \mathrm{~d}$ \\
\hline F & $8,24 *$ & $14,06^{* *}$ & $1,40 \mathrm{~ns}$ & $8,11^{* *}$ & $18,45^{* *}$ & $6,23^{* *}$ \\
DMS & 7,86 & 0,62 & 8,28 & 0,42 & 0,16 & 0,29 \\
CV(\%) & 14,06 & 13,60 & 16,51 & 19,32 & 24,00 & 25,91 \\
\hline
\end{tabular}

*Médias seguidas pela mesma letra, na coluna, não diferem entre si pelo teste Tukey 5\%. T1 - 100\% Plantmax®; T2 - Plantmax® + NPK + calcário; T3Plantmax ${ }^{\circledR}+$ calcário + N; T4 - Plantmax ${ }^{\circledR}$ + calcário + P; T5 - Plantmax ${ }^{\circledR}$ + calcário + K; T6 - Plantmax ${ }^{\circledR}$ + N; T7 - Plantmax ${ }^{\circledR}+$ P; T8 - Plantmax ${ }^{\circledR}$ + K; T9 - Plantmax ${ }^{\circledR}+$ calcário.

$\mathrm{O}$ crescimento em altura tendeu a um aumento em T4 (Plantmax ${ }^{\circledR}+$ calcário + P), T5 $\left(\right.$ Plantmax ${ }^{\circledR}+$ calcário $\left.+\mathrm{K}\right)$, T6 (Plantmax ${ }^{\circledR}+$ N) e T7 (Plantmax $\left.{ }^{\circledR}+\mathrm{P}\right)$, com médias de 34,33 $\mathrm{cm}, 33,50 \mathrm{~cm}, 33,17 \mathrm{~cm}$ e $32,00 \mathrm{~cm}$, respectivamente. Essas médias foram $41,7 \%$, $40 \%, 39,7 \%, 37,5 \%$, superiores às obtidas em T9 (Plantmax ${ }^{\circledR}+$ calcário). Demonstrando que, ao utilizar apenas o substrato comercial a planta pode não atingir o seu máximo potencial de crescimento porque a quantidade de nutrientes que o mesmo possui pode não ser suficiente para ela. Além disso, apenas a adição de calcário ao substrato não foi suficiente para aumentar o crescimento das mudas, ao passo que, a adição de macronutrientes ( $\mathrm{N}, \mathrm{P}$ e $\mathrm{K}$ ) melhorou as condições do substrato promovendo maior incremento no crescimento.

Com relação ao diâmetro, houve tendência de aumento no crescimento das mudas em T3 $\left(\right.$ Plantmax ${ }^{\circledR}+$ calcário $\left.+\mathrm{N}\right)$, com média de 3,02 mm, que foi $60 \%$ superior ao T9 (Plantmax ${ }^{\circledR}+$ 
calcário), reforçando os resultados obtidos para o crescimento em altura. Enquanto que, para o crescimento do sistema radicular não se observou diferença estatística, porém, todos os tratamentos possibilitaram médias superiores a $20 \mathrm{~cm}$. Essa característica é importante porque aumenta a eficiência da planta em absorver água e nutrientes. Um exemplo é o $\mathrm{K}$, que é predominantemente absorvido por difusão, portanto, um maior volume de raízes favorece o contato com o nutriente (MATOS et al., 2012), além de favorecer a absorção dos demais nutrientes, o que pode ter contribuído para o crescimento em altura das mudas de $E$. camaldulensis.

A altura e o diâmetro do colo das mudas plantadas no campo devem ser de 20 a $40 \mathrm{~cm}$ e de 2,0 $\mathrm{mm}$, respectivamente (XAVIER et al., 2009), dessa forma, T8 (Plantmax $\left.{ }^{\circledR}+\mathrm{K}\right)$ e T9 (Plantmax ${ }^{\circledR}+$ calcário) seriam os tratamentos menos indicados porque demorariam mais para atingir esses valores. $\mathrm{O}$ menor crescimento nesses tratamentos pode estar relacionado ao menor potencial nutritivo do substrato.

A produção de biomassa das folhas está diretamente relacionada à capacidade fotossintética da planta e isso influencia no crescimento das mudas. Nesse caso, T1 (100\% Plantmax $\left.{ }^{\circledR}\right)$ foi o que proporcionou a maior média, de 1,59 g, que foi 53\% superior à de T8 (Plantmax $\left.{ }^{\circledR}+\mathrm{K}\right)$. Portanto, as condições promovidas pelo substrato comercial favoreceram a produção de biomassa das plantas, porém, sem garantir médias superiores para os crescimentos em altura e em diâmetro. Resultados semelhantes foram observados para a biomassa do caule, em que a maior média foi obtida em T1 (100\% Plantmax®), que foi $86 \%$ superior à de T9 (Plantmax ${ }^{\circledR}+$ calcário).

Para a biomassa das raízes, T7 (Plantmax ${ }^{\circledR}+$ P) proporcionou média de $0,81 \mathrm{~g}$, a qual foi $62 \%$ superior à observada em T9 (Plantmax ${ }^{\circledR}+$ calcário), com 0,31 g. A adição de $\mathrm{P}$ favoreceu essa produção porque o elemento está diretamente relacionado com o crescimento radicular e, segundo Stahl et al. (2013) a geometria das raízes influencia no crescimento da planta e na aquisição de nutrientes. Ainda segundo esses autores, o adequado suprimento em $\mathrm{P}$ é importante para a formação dos primórdios vegetativos, uma vez que as raízes de plantas jovens absorvem fosfato mais rapidamente que raízes de plantas mais velhas. Portanto, apesar do calcário melhorar as condições de fertilidade do solo, não foi suficiente para aumentar a produção de biomassa das raízes.

Os resultados obtidos nesse experimento foram superiores aos observados por Lôbo et al. (2014), que registraram altura de $16,41 \mathrm{~cm}$, diâmetro de 1,31 mm, biomassa da parte aérea de 0,186 g e da parte radicular de 0,193 em mudas de E. camaldulensis, produzidas em tubetes preenchidos com substrato comercial Bioplant ${ }^{\circledR}$ adubado com NPK. Assim como por Bernardi et al. (2012), que verificaram o crescimento de Corymbia citriodora em função do uso de hidrogel e adubação, em tubetes preenchidos com substrato comercial, com médias de $16,42 \mathrm{~cm}$ de altura e $2,29 \mathrm{~mm}$ de diâmetro, após 126 dias. Estes estudos e os resultados obtidos no presente experimento, corroboram a importância de enriquecer o substrato comercial quando se objetiva produzir mudas de E. camaldulensis.

Nutrição de mudas de Eucalyptus camaldulensis

A nutrição das mudas de E. camaldulensis foi influenciada pelas combinações entre Plantmax ${ }^{\circledR}$, calcário e adubo, como observa-se na Tabela 3. Para as comparações das concentrações de nutrientes no presente estudo utilizaram-se as recomendações de Malavolta et al. (1997), que foram descritas para E. grandis Hill ex Maiden, isso porque não existem, em literatura, recomendações para o $E$. camaldulensis.

As maiores concentrações de $\mathrm{N}$ foram verificadas em T3 (Plantmax ${ }^{\circledR}+$ calcário + N) devido à melhoria nas condições químicas do substrato e a adição de $\mathrm{N}$, porém, que não foi suficiente para elevar as concentrações até a faixa recomendada por Malavolta et al. (1997), que é de 21 a $23 \mathrm{~g} \mathrm{~kg}^{-1}$. Enquanto que, as menores concentrações de $\mathrm{N}$ foram verificadas 
em T5 (Plantmax ${ }^{\circledR}+$ calcário + K) e T9

(Plantmax ${ }^{\circledR}+$ calcário), o que pode indicar que a adição apenas de calcário pode não ter favorecido o aumento na disponibilidade de $\mathrm{N}$.
No caso de T8, a menor concentração de $\mathrm{N}$ também pode estar relacionada com a menor produção de biomassa das folhas.

Tabela 3 - Concentrações de macronutrientes $\left(\mathrm{g} \mathrm{kg}^{-1}\right)$ e de $\mathrm{B}\left(\mathrm{mg} \mathrm{kg}^{-1}\right)$, nas folhas das mudas de Eucalyptus camaldulensis produzidas em combinações de substrato comercial, adubo e calcário

Table 3 - Concentrations of macronutrients $\left(\mathrm{g} \mathrm{kg}^{-1}\right)$ and B $\left(\mathrm{mg} \mathrm{kg}^{-1}\right)$ on leaves of Eucalyptus camaldulensis seedlings produced in commercial substrate, fertilizer and limestone combinations

\begin{tabular}{cccccccc}
\hline Trat.* & $\mathbf{N}$ & $\mathbf{P}$ & $\mathbf{K}$ & $\mathbf{C a}$ & $\mathbf{M g}$ & $\mathbf{S}$ & $\mathbf{B}$ \\
\hline T1 & $10,25 \mathrm{bc} *$ & $12,25 \mathrm{~cd}$ & $14,58 \mathrm{ab}$ & $1,08 \mathrm{a}$ & $0,30 \mathrm{~b}$ & $1,89 \mathrm{bcd}$ & $108,28 \mathrm{ab}$ \\
T2 & $13,38 \mathrm{ab}$ & $17,70 \mathrm{a}$ & $15,07 \mathrm{ab}$ & $0,83 \mathrm{ab}$ & $0,84 \mathrm{a}$ & $2,37 \mathrm{~b}$ & $116,33 \mathrm{a}$ \\
T3 & $17,08 \mathrm{a}$ & $18,64 \mathrm{a}$ & $16,92 \mathrm{a}$ & $0,77 \mathrm{ab}$ & $1,07 \mathrm{a}$ & $2,95 \mathrm{a}$ & $119,32 \mathrm{a}$ \\
T4 & $10,98 \mathrm{bc}$ & $15,50 \mathrm{abc}$ & $16,38 \mathrm{a}$ & $0,70 \mathrm{~b}$ & $0,96 \mathrm{a}$ & $1,61 \mathrm{cde}$ & $88,72 \mathrm{~cd}$ \\
T5 & $8,62 \mathrm{c}$ & $12,67 \mathrm{bcd}$ & $16,04 \mathrm{a}$ & $0,77 \mathrm{ab}$ & $0,88 \mathrm{a}$ & $1,08 \mathrm{fg}$ & $80,31 \mathrm{~cd}$ \\
T6 & $11,82 \mathrm{bc}$ & $16,24 \mathrm{ab}$ & $12,40 \mathrm{bc}$ & $0,77 \mathrm{ab}$ & $0,80 \mathrm{a}$ & $1,46 \mathrm{def}$ & $94,16 \mathrm{bc}$ \\
T7 & $10,19 \mathrm{bc}$ & $12,01 \mathrm{~cd}$ & $11,18 \mathrm{c}$ & $0,89 \mathrm{ab}$ & $0,88 \mathrm{a}$ & $1,99 \mathrm{bc}$ & $88,78 \mathrm{~cd}$ \\
T8 & $9,74 \mathrm{bc}$ & $13,35 \mathrm{bcd}$ & $15,85 \mathrm{a}$ & $0,96 \mathrm{ab}$ & $0,77 \mathrm{ab}$ & $1,34 \mathrm{ef}$ & $74,64 \mathrm{~d}$ \\
T9 & $8,90 \mathrm{c}$ & $9,92 \mathrm{~d}$ & $10,11 \mathrm{c}$ & $0,96 \mathrm{ab}$ & $0,69 \mathrm{ab}$ & $0,62 \mathrm{~g}$ & $17,18 \mathrm{e}$ \\
\hline F & $7,62 * *$ & $14,34 * *$ & $16,23 * *$ & $2,83 *$ & $4,27 * *$ & $38,56^{* *}$ & $81,77 * *$ \\
DMS & 4,45 & 3,58 & 2,84 & 0,34 & 0,49 & 0,52 & 15,76 \\
CV $(\%)$ & 19,05 & 12,06 & 9,54 & 19,20 & 29,19 & 14,71
\end{tabular}

*Médias seguidas pela mesma letra, na coluna, não diferem entre si pelo teste Tukey 5\%. T1 - 100\% Plantmax®; T2 - Plantmax ${ }^{\circledR}+$ NPK + calcário; T3- Plantmax ${ }^{\circledR}$ + calcário + N; T4 - Plantmax ${ }^{\circledR}$ + calcário + P; T5 - Plantmax ${ }^{\circledR}$ + calcário + K; T6 - Plantmax ${ }^{\circledR}$ + N; T7 Plantmax ${ }^{\circledR}+$ P; T8 - Plantmax ${ }^{\circledR}+$ K; T9 - Plantmax ${ }^{\circledR}+$ calcário.

Todos os tratamentos testados proporcionaram altas concentrações de $\mathrm{P}$, possivelmente pelos teores já existentes no substrato, o que não incorreu em limitações no crescimento das plantas. Nesse caso, as maiores médias foram observadas em T2 (Plantmax ${ }^{\circledR}+$ NPK + calcário) e T3 (Plantmax ${ }^{\circledR}+$ calcário + $\mathrm{N})$, pois, o calcário aumenta os teores de bases e, por consequências, a saturação por bases e o pH do solo, diminuindo a adsorção do $\mathrm{P}$.

Para as concentrações de $\mathrm{K}$, apenas em T9 (Plantmax ${ }^{\circledR}+$ calcário) observou-se níveis adequados, considerando Malavolta et al. (1997), entre 9 e $10 \mathrm{~g} \mathrm{~kg}^{-1}$. Nos demais, estiveram acima da faixa recomendada, sendo que, as maiores médias foram verificadas em T3 $\left(\right.$ Plantmax ${ }^{\circledR}+$ calcário $\left.+\mathrm{N}\right)$, T4 (Plantmax ${ }^{\circledR}+$ calcário + P), T5 (Plantmax ${ }^{\circledR}+$ calcário $\left.+\mathrm{K}\right)$ e T8 (Plantmax $\left.{ }^{\circledR}+\mathrm{K}\right)$. Isto indica que o substrato possui concentrações adequadas de $\mathrm{K}$, condizente com o requerimento da espécie.

As menores concentrações de $\mathrm{Ca}$ e de $\mathrm{Mg}$ nas mudas de E. camaldulensis podem estar relacionadas às exigências da espécie, pois estas não apresentaram sintomas de deficiências no período de análise do experimento, resultado também observado por Costa Filho et al. (2013), em mudas de Mimosa caesalpinifolia, produzidas em viveiro. Assim como por Sena et al. (2010), que observaram que a absorção de $\mathrm{Mg}$ não foi influenciada pela correção da acidez nem pela adição de $\mathrm{Ca}$ e $\mathrm{Mg}$ em mudas de Dinizia excelsa em condições de viveiro. Segundo os autores, isso sugere que essas espécies podem não ser tão exigentes nestes nutrientes, ou que a quantidade deles, presentes no solo, foi suficiente para suprir as necessidades das plantas. O que pode ter ocorrido no presente caso.

As maiores concentrações de $\mathrm{S}$ foram observadas em T3 (Plantmax ${ }^{\circledR}+$ calcário $\left.+\mathrm{N}\right)$, porém, apenas em T9 (Plantmax ${ }^{\circledR}+$ calcário) não estiveram dentro da faixa adequada recomendada por Malavolta et al. (1997). Indicando que, apenas o Plantmax ${ }^{\circledR}$ não foi eficiente na liberação de $\mathrm{S}$ e, a adição de calcário 
também não aumentou a disponibilização do mesmo. Por isso, os demais tratamentos foram considerados melhores, pois a adição de $\mathrm{P}_{2} \mathrm{O}_{5}$ na forma de super simples, que também contém $\mathrm{S}$ e; a adição de $\mathrm{N}$ e de $\mathrm{K}$, facilitaram a liberação de $\mathrm{S}$.

Em relação à concentração de $\mathrm{B}, \quad \mathrm{T} 2$ (Plantmax ${ }^{\circledR}+$ NPK + calcário) e T3 (Plantmax ${ }^{\circledR}$ + calcário $+\mathrm{N}$ ) foram os que proporcionaram as maiores médias, porém, apenas em T9 (Plantmax ${ }^{\circledR}+$ calcário) estiveram abaixo das médias recomendadas por Malavolta et al. (1997). Nos demais, as concentrações de B estiveram acima da ideal, o que auxilia a explicar o menor crescimento em T9. Nesse caso, a aplicação do calcário pode ter elevado o $\mathrm{pH}$ a um nível em que reduziu a solubilidade de B no solo, enquanto os demais tratamentos podem ter possibilitado interações positivas no solo e favorecido a disponibilidade do B.

Carvalho Filho et al. (2003), enfatizaram que, as melhores condições do substrato não estão apenas no suprimento de nutrientes, mas também na melhoria de outros constituintes da fertilidade do solo e aeração, no fornecimento de água, entre outros, o que foi atingido em substratos contendo Plantmax ${ }^{\circledR}$ com calcário e/ou adubação com $\mathrm{N}$ ou com $\mathrm{P}$. Isso porque, de acordo com Dias et al. (2015), apesar dos solos cultivados com eucalipto, no Brasil, apresentarem elevada acidez, sua resposta à prática da calagem nem sempre é verificada. No entanto, a solubilidade do fertilizante e a consequente disponibilidade de $\mathrm{P}$ são bastante influenciadas pelo $\mathrm{pH}$ do solo.

\section{Conclusões}

Houve melhora das condições químicas do solo após a aplicação de calcário e/ou de adubos ao substrato comercial que incorreu em tendência de maior incremento em altura, diâmetro e biomassa seca nas mudas de $E$. camaldulensis.

As melhores condições para a produção de mudas de E. camaldulensis foram verificadas em substratos compostos por Plantmax ${ }^{\circledR}+$ calcário
$+\mathrm{N}$; por Plantmax ${ }^{\circledR}+$ calcário $+\mathrm{P}$; por Plantmax ${ }^{\circledR}+\mathrm{N}$; e por Plantmax ${ }^{\circledR}+\mathrm{P}$.

\section{Referências Bibliográficas}

BERNARDI, M. R. et al. Crescimento de mudas de Corymbia citriodora em função do uso de hidrogel e adubação. Cerne, v. 18, n. 1, p. 6774, 2012.

CARLOS, L. et al. Crescimento e nutrição mineral de mudas de pequi sob efeito da omissão de nutrientes. Ciência Florestal, v. 24, n. 1, p. 13-21, 2014.

CARVALHO FILHO, J. L. S. et al. Produção de mudas de jatobá (Hymenaea courbaril L.) em diferentes ambientes, recipientes e composições de substratos. Cerne, v. 9, n. 1, p. 09-118, 2003.

COSTA FILHO, R. T.; VALERI, S. V.; CRUZ, M. C. P. Calagem e adubação fosfatada no crescimento de mudas de Mimosa caesalpinifolia Benth. em latossolo vermelhoamarelo. Ciência Florestal, v. 23, n. 1, p. 89-93, 2013.

DEL QUIQUI, E. M.; MARTINS, S. S.; SHIMIZU, J. Y. Avaliação de espécies e procedências de Eucalyptus spp. para o noroeste do estado do Paraná. Acta Scientiarum, v. 23, n. 5, p. 1173-1177, 2001.

DIAS, L. P. R. et al. Eficiência relativa de fosfatos naturais na adubação de plantio de mudas de Eucalyptus dunnii Maiden e Eucalyptus benthamii Maiden et Cambage em solo sem e com calagem. Ciência Florestal, v. 25, n. 1, p. 37-48, 2015.

EMPRESA BRASILEIRA DE PESQUISA AGROPECUÁRIA - EMBRAPA. Serviço Nacional de Levantamento e Conservação de Solos. Manual de métodos de análise do solo. 2. ed. Rio de Janeiro: EMBRAPA, 1997. 212 p. 
FAVARE, L. G.; GUERRINI, I. A.; BACKES, C. Níveis crescentes de saturação por bases e desenvolvimento inicial de teca em um Latossolo de textura média. Ciência Florestal, v. 22, n. 4, p. 693-702, 2012.

FEITOSA, D. G. et al. Crescimento de mudas de gonçalo-alves (Astronium fraxinifolium) sob diferentes fontes e doses de nitrogênio. Revista Árvore, v. 35, n. 3, p. 401-411, 2011.

GONÇALVES, J. L. M. Recomendação de adubação para Eucalyptus, Pinus e espécies típicas da Mata Atlântica. Documentos Florestais, Piracicaba, v.15, p.1-23, 1995.

INDÚSTRIA BRASILEIRA DE ÁRVORES IBA. Anuário Estatístico IBÁ 2016. Brasília: IBÁ, 2016. 96 p.

LÔBO, L. M. et al. Crescimento de mudas de Eucalyptus camaldulensis em resposta à fertilização NPK. Global Science Technology, v. 7, n. 2, p. 74-80, 2014.

MALAVOLTA, E.; VITTI, G. C.; OLIVEIRA, S. A. Avaliação do estado nutricional das plantas: princípios e aplicações. 2. ed. Piracicaba: POTAFOS, 1997. 319 p.

MATOS, G. S. B. et al. Desenvolvimento inicial e estado nutricional de clones de eucalipto no nordeste do Pará. Acta Amazônica, v. 42, n. 4, p. 491-500, 2012.

MORAES NETO, S. P. O eucalipto no Cerrado do DF: plantio puro e sistema agrossilvipastoril. 2008. Artigo em Hypertexto. Disponível em: <http://www.infobibos.com/Artigos/2008_1/eu calipto/index.htm>. Acesso em: 31 jul. 2015.

MUNIZ, C. O. et al. Efeito de diferentes adubos NPK no processo de produção de mudas de eucalipto. Enciclopédia Biosfera, v. 9, n. 17, p. 1162-1168, 2013.
OLIVEIRA, J. R. et al. Saturação por bases para o cultivo do cedro australiano. Global Science and Thechnology, v. 8, n. 2, p. 96-102, 2015.

SCHEER, M. B.; CARNEIRO, C.; SANTOS, K. G. Substratos à base de lodo de esgoto compostado na produção de mudas de Parapiptadenia rigida (Benth.) Brenan. Scientia Forestalis, v. 38, n. 88, p. 637-644, 2010.

SENA, J. S. et al. Efeito da calagem e da correção dos teores de $\mathrm{Ca}$ e $\mathrm{Mg}$ do solo sobre o crescimento de mudas de angelim-pedra (Dinizia excelsa Ducke). Acta Amazônica, v. 40, n. 2, p. 309-318, 2010.

SILVA, F. A. S. Assistat - assistência estatística, versão 7.6 (Beta). Campina Grande: UFCG, 2011.

STAHL, J. et al. Produção de massa seca e eficiência nutricional de clones de Eucalyptus dunni e Eucalyptus benthamii em função da adição de doses de fósforo ao solo. Ciência Florestal, v. 23, n. 2, p. 287-295, 2013.

XAVIER, A.; WENDLING, I.; SILVA, R. L. Silvicultura clonal: princípios e técnicas. Viçosa: UFV, 2009. 272 p. 